\title{
Efeito do Genótipo Halotano e de Diferentes Sistemas de Produção no Desempenho Produtivo e na Qualidade da Carcaça Suína ${ }^{1}$
}

\author{
Ana Maria Bridi², Sergio Nicolaiewsky ${ }^{3}$, Jane Maria Rübensam ${ }^{4}$, Maria do Carmo Both ${ }^{5}$, \\ José Fernando Piva Lobato6
}

\begin{abstract}
RESUMO - O objetivo deste trabalho foi verificar o efeito dos genótipos halotano homozigoto dominante e heterozigoto e de três sistemas de criação (confinado sobre piso de cimento, confinado sobre cama de maravalha e ao ar livre) no desempenho produtivo e na qualidade da carcaça e da carne suína. Foram utilizados 96 suínos machos castrados selecionados pelo exame de DNA genômico no sangue utilizando-se a técnica de reação em cadeia da polimerase (PCR) para amplificar a região do receptor rianodina. A região amplificada foi clivada pela técnica do polimorfismo do comprimento dos fragmentos de restrição (RFLP). Nas fases de crescimento e terminação, avaliaram-se ganho de peso, consumo de ração e conversão alimentar. Após o abate, as carcaças foram pesadas e tipificadas eletronicamente. Vinte e quatro horas após o abate, foram separados e pesados o pernil e o carrê e medida a área de olho de lombo. A presença do gene halotano não afetou o desempenho dos suínos, mas aumentou a porcentagem de carne magra e diminuiu a quantidade de gordura na carcaça. Suínos criados no sistema intensivo ao ar livre apresentaram menor ganho de peso e pior conversão alimentar. No sistema intensivo de criação confinado sobre cama, os suínos produziram carcaças com menor quantidade de carne magra e maior quantidade de gordura. Não houve efeito significativo da interação genótipo halotano e sistema de criação para as características avaliadas.
\end{abstract}

Palavras-chave: criação ao ar livre, criação sobre cama de maravalha, carne suína, gene halotano

\section{Effect of the Halothane Genes and Rearing Systems on Growth Performance and Pig Carcass Quality}

\begin{abstract}
The objective of this study was to evaluate the effect of the halothane genotypes (heterozygous and dominant homozygous) and intensive rearing systems (indoor, wood shavings bedding and outdoor) on growth performance, carcass and meat yield. Ninety six castrated male pigs were used for the trial. Identification of the halothane genotype was determined in blood samples using the DNA-test, based on the polymerase chain reaction (PCR) for amplification of the critical region of the ryanodine receptor and subsequent restriction of the amplified fragment by restriction fragment lengh polymorfism technique (RFLP). Growth and finishing performance were evaluated by weight gain, feed intake and feed efficiency. Carcass quality was evaluated by backfat and muscle depth, meat percentage through Hennessy Grading Probe and carcass weight. Twenty four hours after slaugther, ham and loin weight were recorded and the loin eye area was evaluated. The growth performance was similar for the two genotypes. The heterozygous pigs for the halothane gene had higher percentage of fat-free lean and less fat in the carcass. Outdoor reared pigs showed lower average daily gain and worst efficiency than pigs reared indoor. Carcasses of pigs reared under wood shavings bed had less fat-free lean and greater backfat thickeness. The interaction between halothane genotypes and rearing systems had no significant effect on any trait studied.
\end{abstract}

Key Words: halothane gene, outdoor rearing system, pork meat, wood shavings bedding

\section{Introdução}

Até o início dos anos 90, só era possível distinguir entre suínos livres do gene halotano $\left(\mathrm{Hal}^{\mathrm{NN}}\right)$ e os portadores $\left(\mathrm{Hal}^{\mathrm{Nn}}\right.$ e $\left.\mathrm{Hal}^{\mathrm{nn}}\right)$. Com a descoberta de Fugii et al. (1991) acerca da mutação que ocorre no receptor rianodina do músculo esquelético, foi possível desenvolver um teste baseado na reação em cadeia da polimerase (PCR) e do polimorfismo do comprimento dos fragmentos de restrição (RLPC). Estas técnicas permitiram a diferenciação dos três genótipos halotano e avançar no entendimento da influência deste gene na produção suinícola.

\footnotetext{
${ }^{1}$ Trabalho originado na tese de doutorado do primeiro autor e parcialmente financiado pelo CNPSA/EMBRAPA.

${ }^{2}$ Aluna de Doutorado do Programa de Pós-Graduação em Zootecnia da UFRGS. Av. Rio de Janeiro, 814, apt 102. Londrina, PR. E.mail: ambridi@hotmail.com

3 Professor Adjunto IV, Departamento de Zootecnia/UFRGS, Caixa Postal 776. CEP: 90.001-970. Porto Alegre. RS. E.mail: nicola@vortex.ufrgs.br

${ }^{4}$ Professora Adjunto IV,Faculdade deVeterinária/UFRGS. Av. Bento Gonçalves 9090. Caixa Postal: 15094. CEP 91540-000. Porto Alegre.

RS. E.mail: jane@orion.ufrgs.br

5 Aluna de Doutorado do Programa de Pós-Graduação em Zootecnia da UFRGS. Rua Concórdia, 484. CEP: 92120-140. Canoas, RS. E.mail: E.mail: mcboth@terra.com.br

6 Professor Adjunto IV, Departamento de Zootecnia/UFRGS, Caixa Postal 776, CEP: 90.001-970. Porto Alegre. RS. E.mail: lobato@orion.ufrgs.br
} 
Existe muita contradição na literatura a respeito de ser recessiva ou aditiva a ação do gene halotano sobre o desempenho e a qualidade da carne. Comercialmente, o gene halotano é de interesse porque melhora a conversão alimentar (Leach et al, 1996, Christian, 1997; Ellis, 1998a), aumenta o conteúdo de carne e diminui a deposição de gordura na carcaça (Oliver et al., 1993; Antunes, 1997; Culau, 1999; Gispert et al., 2000). Entretanto, suínos portadores do alelo recessivo do gene halotano, em comparação aos homozigotos dominantes, são mais susceptíveis ao estresse e produzem carne de qualidade inferior, particularmente por aumentar a incidência de carne PSE, sigla internacional para denominar carne de coloração pálida, de textura mole e exsudativa (Cheah et al., 1995; Leach, et al., 1996; Ellis, 1998b; Culau, 1999).

O setor suinícola precisa, além de fornecer carne em quantidade e qualidade adequada, resolve o destino dos grandes volumes de fezes e urina produzidos, os quais são fontes de poluição que causam a contaminação das águas superficiais e subterrâneas. A produção de suínos ao ar livre ou sobre cama pode ser uma alternativa viável de manejo, tratamento e valorização agronômica dos efluentes suínos.

O objetivo deste trabalho foi investigar o efeito dos genótipos halotano homozigoto dominante $\left(\mathrm{Hal}^{\mathrm{NN}}\right)$ e heterozigoto $\left(\mathrm{Hal}^{\mathrm{Nn}}\right)$ e dos sistemas de produção confinado sobre piso de concreto, confinado sobre cama de maravalha e ao ar livre no desempenho de suínos durante as fases de crescimento e terminação e na qualidade da carcaça suína.

\section{Material e Métodos}

O experimento foi conduzido na Estação Experimental da Faculdade de Agronomia, da Universidade
Federal do Rio Grande do Sul, localizada no município de Eldorado do Sul, RS, nos meses de abril a julho de 2000. Os animais foram abatidos no matadouro frigorífico Doux Frangosul, localizado na cidade de Caxias do Sul, RS, distante $150 \mathrm{~km}$ da Estação Experimental Agronômica.

Foram utilizados 96 suínos machos castrados da genética AGROCERES ${ }^{\circledR}$ provenientes do cruzamento de fêmeas CAMBROUGH 22 e machos AGPIC 419. Os animais foram selecionados com menos de 60 dias de idade, através do exame de DNA genômico.

O DNA genômico foi extraído a partir de amostras de sangue (Miller et al.,1988) e submetido à reação em cadeia de polimerase (PCR). Utilizou-se um par de oligonucleotídeos específicos (MHF: 5'GTTCCCTGTGTGTGTGCAATGGTG-3' e MH-R: 5'ATCTCTAGAGCCAGGGAGCAAGTTCTCAGTAAT-3') para amplificação da seqüência de DNA do gene receptor rianodina suíno (Fujii et al., 1991). Os produtos de amplificação foram clivados com a enzima HhaI, por intermédio da técnica polimorfismo do comprimento dos fragmentos de restrição (RFLP), e submetidos à eletroforese em géis de agarose (Sambrook et al., 1989). A digestão do fragmento com a enzima de restrição HhaI produziu dois fragmentos de 49 e 32 pares de bases para suínos homozigotos normais, três frasmentos de 49, 32 e 81 pares de bases para heterozigotos e um fragmento de 81 pares de bases para os suínos homozigotos recessivos mutantes.

$\mathrm{O}$ delineamento experimental utilizado foi $\mathrm{em}$ blocos casualizados em esquema fatorial $2 \times 3$, dois genótipos, (homozigotos dominantes e heterozigotos para o gene halotano) e três sistemas de produção (confinado sobre cimento, confinado sobre cama de maravalha e ao ar livre), com quatro repetições, com

Tabela 1 - Peso médio dos suínos ao início do experimento Table 1 - Initial mean weight of pigs

\begin{tabular}{lccc}
\hline $\begin{array}{l}\text { Genótipo } \\
\text { Genotype }\end{array}$ & $\begin{array}{c}\text { Peso inicial }(\mathrm{kg}) \\
\text { Initial weight }(\mathrm{kg})\end{array}$ & $\begin{array}{c}\text { Erro-padrão } \\
\text { Standard error }\end{array}$ & $\begin{array}{c}\text { Nível de significância } \\
\text { Level of significance }\end{array}$ \\
\hline $\mathrm{Hal}^{\mathrm{NN}}$ & 35,5 & 0,49 & 0,889 \\
$\mathrm{Hal}^{\mathrm{Nn}}$ & 35,6 & 0,49 & 0,383 \\
Sistema & & & 0,60 \\
$\begin{array}{l}\text { Rearing system } \\
\text { Sem cama }\end{array}$ & 35,2 & 0,60 & \\
$\begin{array}{l}\text { Indoors without bedding } \\
\text { Com cama }\end{array}$ & 35,3 & & \\
$\begin{array}{l}\text { Indoors with wood shavings bedding } \\
\text { Ar livre }\end{array}$ & 36,2 & & \\
Outdoors & & & \\
\hline
\end{tabular}

R. Bras. Zootec., v.32, n.4, p.942-950, 2003 
parcelas constituídas por quatro animais. Os blocos foram formados a partir do peso inicial dos suínos. $\mathrm{Na}$ Tabela 1, encontram-se os pesos médios dos suínos ao início do experimento.

Os suínos foram alojados em baias ou piquetes em grupos de quatro animais. As baias mediam 4,6 m de comprimento e $1,80 \mathrm{~m}$ de largura, correspondendo a uma área de $2 \mathrm{~m}^{2}$ por animal. As baias utilizadas pelos suínos do tratamento com cama receberam uma camada de aproximadamente $30 \mathrm{~cm}$ de maravalha, que era trocada parcialmente sempre que alguma área se encontrava úmida. O sistema de criação intensivo ao ar livre estava localizado em uma área ao lado do galpão de terminação. Constituiu-se de 16 piquetes de $500 \mathrm{~m}^{2}$ cada, sendo a densidade de $125 \mathrm{~m}^{2}$ por animal. Os piquetes foram usados em forma de rodízio, para evitar a compactação do solo.

Todos os animais do experimento receberam a mesma ração comercial à vontade. A ração inicial continha 3,38 Mcal de energia metabolizável por quilo de ração e $18 \%$ de proteína bruta, enquanto as rações de crescimento e terminação possuíam, respectivamente, 3,30 e 3,25 Mcal de energia metabolizável e 17 e $16 \%$ de proteína bruta por quilo de ração. A quantidade de ração fornecida por baia e por piquete era pesada, sendo as perdas subtraídas do total de cada baia. Nas fases de crescimento e terminação, avaliouse o ganho de peso, consumo de ração e conversão alimentar. Para facilitar a coleta dos dados no frigorífico, os animais foram abatidos em dois grupos, com diferença de uma semana entre os abates.

No abatedouro as carcaças foram pesadas logo após o abate e após 24 horas de resfriamento, entre 0 a $2^{\circ} \mathrm{C}$. Aproximadamente 30 minutos após o abate, as carcaças foram tipificadas eletronicamente com o auxílio do aparelho de fibra óptica Hennessy Grading Probe, que permitiu obter, na altura da última costela, a espessura de gordura e a profundidade do músculo Longissimus dorsi. A porcentagem de carne magra na carcaça foi obtida através da multiplicação do peso da carcaça quente pela porcentagem de carne magra da carcaça. Vinte e quatro horas após o abate foram separados e pesados o pernil e o carrê. Em amostras descongeladas do músculo Longissimus dorsi, mediu-se a área do músculo utilizando-se a técnica de contagem de pontos, com o uso de papel milimetrado.

Estimativas de consumo diário médio de ração e de conversão alimentar foram obtidas usando-se as informações obtidas de cada baia. O modelo mate- mático utilizado para a análise dos dados foi:

$$
\mathrm{Y}_{\mathrm{ijkl}}=\mu+\mathrm{B}_{\mathrm{i}}+\mathrm{G}_{\mathrm{j}}+\mathrm{S}_{\mathrm{k}}+(\mathrm{GS})_{\mathrm{jk}}+\mathrm{e}_{\mathrm{ijkl}}
$$

em que: $Y_{i j k l}=$ fator a ser analisado (variável dependente); $\mathrm{m}=$ média geral; $\mathrm{B}_{\mathrm{i}}=$ efeito do i-ésimo bloco; $\mathrm{G}_{\mathrm{j}}=$ efeito do j-ésimo genótipo; $\mathrm{S}_{\mathrm{k}}=$ efeito do k-ésimo sistema; $(\mathrm{GS})_{\mathrm{jk}}=$ interação genótipo com o sistema; $\mathrm{e}_{\mathrm{ijk}} \mathrm{l}=$ erro associado à repetição.

Para as variáveis relacionadas à qualidade da carcaça, o modelo matemático não levou em conta o efeito bloco, sendo cada animal considerado como uma unidade experimental. Acrescentou-se ao modelo o dia do abate como um fator de variação.

Métodos de análise estatística descritiva convencional foram usados para calcular a média e o erro padrão. Foi realizada análise da variância pelo programa estatístico STATGRAPHICS (Statistical Graphics System, versão 7,0 - STSC, Inc. and Statistical Graphics Corporation, 1985-91). As médias foram comparadas pelo teste Tukey.

\section{Resultados e Discussão}

O efeito do genótipo halotano e dos diferentes sistemas de criação no desempenho produtivo dos suínos é visualizado na Tabela 2. O ganho de peso total e diário dos suínos durante o período experimental, não foi influenciado pelo genótipo halotano. Resultados semelhantes foram verificados por Sather et al. (1991) e Leach et al. (1996).

Suínos criados no sistema intensivo ao ar livre apresentaram ganho de peso total e diário inferior aos criados nos sistemas intensivo confinado sobre piso de cimento e sobre cama de maravalha. Em média, os suínos criados no confinamento ganharam $19 \mathrm{~g} /$ dia a mais que os criados ao ar livre. Os resultados encontrados estão de acordo com Jones et al. (1993), Enfält et al. (1997) e Sather et al. (1997).

Os resultados deste trabalho discordam dos obtidos por Irgang et al. (1992) e Bridi et al. (1998). Os autores não encontraram diferenças significativas no ganho de peso dos animais criados nos sistemas confinado e ao ar livre durante as fases de crescimento e a terminação.

Não foram verificadas diferenças significativas para os valores médios de ganho de peso total e diário entre os sistemas confinado sobre piso de concreto e sobre cama de maravalha. Resultados semelhantes foram obtidos por Perdomo et al. (1997) e Corrêa (1998). No entanto, Morgan et al. (1998) observaram que os suínos criados no confinamento sobre cama 
Tabela 2 - Efeito do genótipo halotano e dos sistemas de criação sobre o desempenho produtivo de suínos (média, erro padrão e nível de significância - NS)

Table 2 - Genotype effects and rearing system on the growth peformance of pigs (means, standard errors and level of significance - LS)

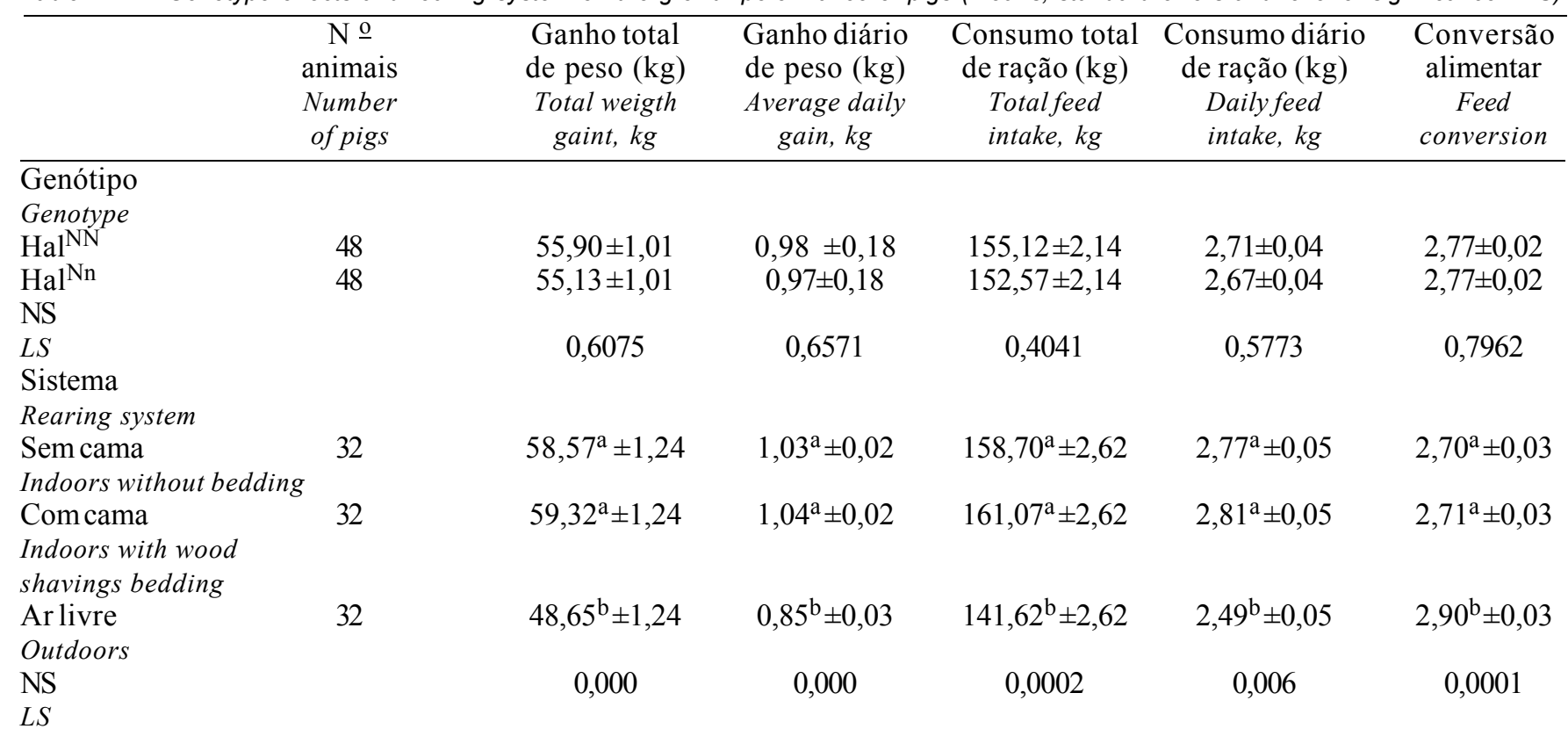

a,b Médias seguidas de letras diferentes na mesma coluna demonstram diferença significativa $(P<0,01)$.

$a, b$ Means with different letter in the same column are significantly different $(P<.01)$.

ganharam, em média, $62 \mathrm{~g} / \mathrm{dia}$ a mais que aqueles criados no confinamento sobre piso de concreto. Comparando-se os dois sistemas de produção, Oliveira (2000) verificou tendência de os suínos criados sobre cama ganharem mais peso à medida que a temperatura ambiente diminuía. Entretanto, na época quente os suínos criados no sistema confinado sobre piso de concreto ganharam mais peso em relação aos suínos criados nos outros sistemas.

O peso vivo alcançado pelos suínos ao final do experimento não foi afetado $(\mathrm{P}>0,05)$ pelo genótipo halotano. Suínos com genótipo halotano homozigoto dominante tiveram peso médio de 90,96 $\mathrm{kg}( \pm 1,13)$ e aqueles com genótipo heterozigoto de $91,19 \mathrm{~kg}( \pm 1,13)$.

O sistema de produção provocou diferenças significativas no peso vivo final dos suínos. Suínos criados no sistema de produção intensivo ao ar livre apresentaram peso médio final inferior aos criados no confinamento sobre piso de concreto e sobre cama de maravalha, que não diferiram entre si. Os valores médios de peso final foram de $84,1 \mathrm{~kg}( \pm 1,39)$ para os suínos criados ao ar livre, 94,0 kg $( \pm 1,39)$ para os criados em confinamento sobre piso de concreto e de $95,0( \pm 1,39)$ para os criados em confiamento sobre cama de maravalha.

Os valores médios de consumo de ração e con- versão alimentar não diferiram entre os suínos $\mathrm{Hal}^{\mathrm{NN}}$ e $\mathrm{Hal}^{\mathrm{Nn}}$, discordando de Leach et al. (1996), os quais verificaram melhor conversão alimentar para os suínos heterozigotos, economizando $21 \mathrm{~kg} / \mathrm{ração} /$ suíno para passar de 40 para $125 \mathrm{~kg}$ de peso vivo. Os autores atribuíram a melhor eficiência na conversão alimentar à presença do alelo recessivo no genótipo dos suínos que produziam maior quantidade de tecido magro.

O consumo diário e total de ração foi afetado pelo sistema de produção. Os suínos criados ao ar livre consumiram menores quantidades total e diária de ração do que os criados no confinamento sobre piso de concreto e sobre cama de maravalha, que não diferiram entre si.

Para produzir ganhos semelhantes de peso, Souza et al. (1992) constataram que suínos criados ao ar livre consumiram, em média, menos $31,7 \mathrm{~kg}$ de ração por animal que aqueles do sistema confinado. Irgang et al. (1992) verificaram uma redução de 5\% no consumo médio diário de ração dos suínos no sistema ao ar livre. Jones et al. (1993) observaram maior consumo de ração pelos suínos criados em confinamento. No trabalho desenvolvido por Sather et al. (1997), durante o verão, o consumo de ração foi semelhante nos sistemas confinado sobre cama de maravalha e ao ar livre. Entretanto, no inverno, o

R. Bras. Zootec., v.32, n.4, p.942-950, 2003 
consumo aumentou em $13 \%$ nos suínos criados ao ar livre em relação aos confinados.

Comparando-se os sistemas de produção confinados sobre piso de cimento e sobre cama, Corrêa (1998), Morgan et al. (1998) e Oliveira (2000) observaram que o consumo total de ração dos suínos foi semelhante entre os dois sistemas.

A conversão alimentar foi influenciada pelo sistema de criação. Os valores médios de conversão alimentar demonstraram que os suínos criados em sistema intensivo ao ar livre apresentaram a pior conversão alimentar. Em média, os suínos criados ao ar livre, para ganhar um quilo de peso vivo, precisaram consumir 200 g e 210 g a mais de ração em relação aos criados em confinamento sobre piso de concreto e em confinamento sobre cama de maravalha, respectivamente. Estes resultados discordaram daqueles observados por Jones et al. (1993), que não encontraram diferenças significativas entre os valores médios de conversão alimentar obtidos nos sistemas de criação confinado e ao ar livre. Da mesma forma, os resultados deste trabalho discordaram dos encontrados por Irgang et al. (1992) e Souza et al. (1992) para os quais suínos criados ao ar livre apresentaram melhor conversão alimentar do que os confinados. Segundo Sather et al. (1997), a diferença na conversão alimentar entre os sistemas de produção foi dependente da estação do ano. Suínos criados ao ar livre apresentaram melhor conversão alimentar no verão enquanto os confinados sobre cama de maravalha apresentaram melhor conversão alimentar no inverno.

Os valores médios de conversão alimentar não foram afetados pelos sistemas de criação confinado sobre piso de cimento e sobre cama de maravalha. Esses resultados estão de acordo com Perdomo et al. (1997), Corrêa (1998) e Oliveira (2000).

As características de desempenho dos animais, peso final, ganho de peso diário e total, consumo diário e total de ração e conversão alimentar não sofreram influência da interação entre o genótipos halotano e os sistemas de criação.

Os valores médios das medidas quantitativas das carcaças dos suínos de diferentes genótipos halotano e criados em três sistemas intensivos encontram-se na Tabela 3 .

Em relação ao genótipo, não foram detectadas variações significativas nos valores médios de peso de carcaça quente, rendimento de carcaça, peso de carcaça resfriada e perda da carcaça durante o resfriamento. Warris et al. (1983) analisando suínos com genótipo halotano, verificaram que suínos mais

Tabela 3 - Efeito dos genótipos halotano e dos sistemas de criação sobre as características quantitativas das carcaças suínas (média, erro padrão e nível de significância - NS)

Table 3 - Genotype effects and rearing system on the carcass characteristics of pigs (means, standard errors and level of significance - LS)

\begin{tabular}{|c|c|c|c|c|c|}
\hline & $\begin{array}{l}\text { Número } \\
\text { animais } \\
\text { Number } \\
\text { of pigs }\end{array}$ & $\begin{array}{c}\text { Peso da carcaça } \\
\text { quente, } \mathrm{Kg} \\
\text { Warm carcass } \\
\text { weight, } K g\end{array}$ & $\begin{array}{c}\text { Rendimento de } \\
\text { carcaça, \% } \\
\text { Dressing } \\
\text { percentage, } \%\end{array}$ & $\begin{array}{l}\text { Peso carcaça } \\
\text { resfriada, Kg } \\
\text { Cold carcass } \\
\text { weight, } K g\end{array}$ & $\begin{array}{c}\text { Perda no } \\
\text { resfriamento, \% } \\
\text { Chilling } \\
\text { loss \% }\end{array}$ \\
\hline \multicolumn{6}{|l|}{ Genótipo } \\
\hline \multicolumn{6}{|l|}{ Genotype } \\
\hline $\mathrm{Hal}^{\mathrm{NN}}$ & 48 & $74,1 \pm 0,82$ & $75,0 \pm 0,32$ & $72,2 \pm 0,83$ & $2,54 \pm 0,23$ \\
\hline $\mathrm{Hal}^{\mathrm{Nn}}$ & 48 & $73,0 \pm 0,79$ & $75,3 \pm 0,31$ & $71,2 \pm 0,79$ & $2,37 \pm 0,22$ \\
\hline NS & & 0,3108 & 0,5486 & 0,3895 & 0,6119 \\
\hline \multicolumn{6}{|l|}{$L S$} \\
\hline \multicolumn{6}{|l|}{ Sistema } \\
\hline \multicolumn{6}{|l|}{ Rearing system } \\
\hline Sem cama & 32 & $74,5^{\mathrm{ab}} \pm 0,98$ & $75,5 \pm 0,39$ & $72,6^{\mathrm{ab}} \pm 0,99$ & $2,62 \pm 0,28$ \\
\hline \multicolumn{6}{|l|}{ Indoors without bedding } \\
\hline Com cama & 32 & $75,0^{\mathrm{a}} \pm 0,98$ & $75,0 \pm 0,39$ & $73,3^{a} \pm 0,99$ & $2,26 \pm 0,28$ \\
\hline \multicolumn{6}{|l|}{ Indoors with wood shavings bedding } \\
\hline Ar livre & 32 & $71,1^{b} \pm 1,2$ & $74,9 \pm 0,47$ & $69,4^{b} \pm 1,22$ & $2,48 \pm 0,34$ \\
\hline \multicolumn{6}{|l|}{ Outdoors } \\
\hline NS & 0,0542 & 0,5677 & 0,0581 & 0,6487 & \\
\hline$L S$ & & & & & \\
\hline
\end{tabular}

a,b Médias seguidas de letras diferentes na mesma coluna demonstram diferença significativa $(P<0,05)$.

$a, b$ Means with different letter in the same column are significantly different $(P<0,05)$. 
sensíveis ao estresse apresentaram carcaças mais pesadas do que os suínos mais resistentes ao estresse. Leach et al. (1996) constataram que suínos $\mathrm{Hal}^{\mathrm{Nn}}$ tiveram melhor rendimento de carcaça e carcaças resfriadas mais pesadas do que os suínos do genótipo $\mathrm{Hal}^{\mathrm{NN}}$. Fisher et al. (2000) também verificaram que os suínos com genótipo $\mathrm{Hal}^{\mathrm{Nn}}$ possuíam maior rendimento de carcaça, porém, os autores não encontraram diferença entre os genótipos quando avaliaram o peso de carcaça quente e resfriada. Rendimentos de carcaça iguais para os genótipos $\mathrm{Hal}^{\mathrm{NN}}$ e Hal ${ }^{\mathrm{Nn}}$ foram encontrados por Sather et al. (1991), Van der Wal et al. (1993), Channon et al. (2000) e Hamilton et al. (2000).

Suínos criados durante um mesmo período de tempo em confinamento sobre cama de maravalha apresentaram peso de carcaça quente $(\mathrm{P}=0,054)$ e carcaça fria $(\mathrm{P}=0,058)$ superiores aos pesos dos suínos criados ao ar livre. As médias observadas para essas características, referentes às carcaças de suínos criados em confinamento sobre piso de cimento, foram intermediários. Resultados semelhantes foram observados por Sather et al. (1997) nas condições do verão canadense. Entretanto, na estação fria, os suínos criados no confinamento sobre cama de maravalha apresentaram peso de carcaça quente semelhante aos do ar livre. Ao comparar as carcaças de suínos criados ao ar livre com as dos criados no confinamento, Bridi et al. (1998) não encontraram diferença significativa para a variável peso de carcaça quente. Oliveira (2000) observou que suínos criados sobre piso de concreto e sobre palha apresentaram o mesmo peso de carcaça quente.

Os três sistemas de criação de suínos estudados proporcionaram médias de rendimento e perda de peso das carcaças durante o resfriamento sem diferença significativa. Do mesmo modo, não se observou diferença significativa entre as médias de peso de carcaça quente, rendimento de carcaça, peso de carcaça fria e perda de peso da carcaça durante o resfriamento quando submetidas à análise da interação genótipo-ambiente.

Na Tabela 4, encontram-se os valores médios, erros-padrão e níveis de significância da tipificação da carcaça de suínos realizadas pelo aparelho Hennessey Grading Probe para os genótipos halotano e sistemas de criação.

Os valores médios de espessura de gordura e profundidade do músculo, medidos por intermédio da pistola de tipificação, no músculo Longissimus dorsi, na altura da última costela, bem como a quantidade de carne magra na carcaça, diferiram significativamente entre os genótipos halotano. Suínos portadores do

Tabela 4 - Efeito dos genótipos halotano e dos sistemas de criação sobre as características quantitativas das carcaças suínas obtidas pelo Hennessey Grading Probe (média, erro padrão e nível de significância - NS)

Table 4 - Genotype effects and rearing system on the quantitative traits of the swine carcass measured through Hennessy Grading Probe (means, standard errors and level of significance - LS)

\begin{tabular}{|c|c|c|c|c|c|}
\hline & $\begin{array}{l}\text { Número } \\
\text { animais } \\
\text { Number } \\
\text { of pigs }\end{array}$ & $\begin{array}{l}\text { Espessura } \\
\text { gordura, mm } \\
\text { Backfat } \\
\text { depth, mm }\end{array}$ & $\begin{array}{l}\text { Profundidade } \\
\text { músculo, mm } \\
\text { Muscle } \\
\text { depth, mm }\end{array}$ & $\begin{array}{c}\text { Porcentagem } \\
\text { carne magra, } \% \\
\text { Lean meat } \\
\text { percentage, } \%\end{array}$ & $\begin{array}{l}\text { Quantidade carne } \\
\text { na carcaça, } \mathrm{kg} \\
\text { Lean weigth in } \\
\text { the carcass, } \mathrm{kg}\end{array}$ \\
\hline \multicolumn{6}{|l|}{ Genótipo } \\
\hline \multicolumn{6}{|l|}{ Genotype } \\
\hline $\mathrm{Hal}^{\mathrm{NN}}$ & 48 & $15,8^{\mathrm{a}} \pm 0,42$ & $54,4^{b} \pm 1,13$ & $54,4^{\mathrm{b}} \pm 0,30$ & $40,3 \pm 0,47$ \\
\hline $\mathrm{Hal}^{\mathrm{Nn}}$ & 48 & $14,7^{b} \pm 0,40$ & $60,7^{a} \pm 1,09$ & $56,0^{\mathrm{a}} \pm 0,29$ & $40,8 \pm 0,45$ \\
\hline \multicolumn{6}{|l|}{ NS } \\
\hline$L S$ & & $0,0591 * *$ & $0,0001 *$ & $0,0003^{*}$ & 0,4244 \\
\hline \multicolumn{6}{|l|}{ Sistema } \\
\hline \multicolumn{6}{|l|}{ Rearing system } \\
\hline \multicolumn{6}{|l|}{ Sem cama } \\
\hline \multicolumn{6}{|l|}{ Indoors without bedding } \\
\hline Com cama & 32 & $17,2^{\mathrm{a}} \pm 0,50$ & $56,6 \pm 1,36$ & $53,8^{b} \pm 0,36$ & $40,1 \pm 0,056$ \\
\hline \multicolumn{6}{|l|}{ Indoors with wood shavings bedding } \\
\hline Ar livre & 32 & $13,3^{b} \pm 0,62$ & $56,6 \pm 1,67$ & $56,2^{\mathrm{a}} \pm 0,45$ & $40,0 \pm 0,69$ \\
\hline \multicolumn{6}{|l|}{ Outdoors } \\
\hline NS & $0,0001 *$ & 0,2819 & $0,0003 *$ & 0,3278 & \\
\hline$L S$ & & & & & \\
\hline
\end{tabular}

R. Bras. Zootec., v.32, n.4, p.942-950, 2003 
gene halotano $\left(\mathrm{Hal}^{\mathrm{Nn}}\right)$ apresentaram, em média, 6,3 $\mathrm{mm}$ a mais na medida de profundidade de músculo o que resultou em $1,6 \%$ a mais de carne magra na carcaça e aproximadamente um milímetro a menos de espessura de gordura em comparação aos suínos livres do gene halotano. Estes resultados foram semelhantes aos obtidos por Antunes (1997), Culau (1999) e Gispert et al. (2000). Entretanto, Gispert et al. (1990) e Sather et al. (1991) não encontraram diferenças significativas para as características de profundidade do músculo e porcentagem de gordura, quando comparados os genótipos.

Os suínos criados no sistema de produção confinado sobre cama de maravalha apresentaram maior espessura de gordura e menor porcentagem de carne magra na carcaça. Suínos criados em confinamento sobre piso de cimento e ao ar livre não diferiram entre si. Comparando-se carcaças de mesmo peso, Van der Wal et al. (1993) constataram que os suínos criados ao ar livre apresentaram tendência a produzir mais gordura subcutânea e menor quantidade de carne magra na carcaça. Entretanto, Jones et al. (1993), Enfält et al. (1997) e Sather et al. (1997) constataram que os suínos criados ao ar livre apresentaram maior quantidade de carne magra e menor proporção de gordura que os suínos terminados em confinamento.

Nos trabalhos desenvolvidos por Jones et al.
(1993) e Bridi et al. (1998) não foram detectadas diferenças significativas nas médias de espessura de gordura e profundidade dos músculos dorsais entre os suínos criados ao ar livre e em confinamento. Comparando-se os sistemas de produção confinado sobre piso de cimento e confinado sobre cama, Corrêa (1998) e Oliveira (2000) não encontraram diferenças significativas entre as médias de porcentagem de carne magra na carcaça, profundidade do músculo e espessura de gordura entre os dois sistemas.

A análise da interação entre genótipos halotano e os sistemas de criação estudados não mostrou efeito significativo sobre as características de carcaça de suínos obtidas pela tipificação.

O efeito do genótipo halotano e dos sistemas de criação sobre a área de olho de lombo e sobre os pesos do pernil e do carrê encontram-se na Tabela 5 .

Suínos com genótipo $\mathrm{Hal}^{\mathrm{Nn}}$ apresentaram, em média, $3,2 \mathrm{~cm}^{2}$ a mais de área de olho de lombo do que os suínos $\mathrm{Hal}^{\mathrm{NN}}(\mathrm{P}=0,0042)$. Estes resultados discordaram dos encontrados por Leach et al. (1996) que não verificaram diferenças significativas entre os valores médios de área de olho de lombo entre os genótipos suínos $\mathrm{Hal}^{\mathrm{NN}}$ e $\mathrm{Hal}^{\mathrm{Nn}}$. Os valores médios dos pesos dos pernil e do carrê não foram influenciados pela presença ou não do alelo recessivo halotano. Entretanto, Leach et al. (1996) verificaram que suínos

Tabela 5 - Efeito dos genótipos halotano e dos sistemas de criação sobre a área de olho de lombo e nos pesos do pernil e do carrê (média, erro padrão e nível de significância - NS)

Table 5 - Genotype effects and rearing system on the loin eye area and ham and loin weight (means, standard errors and level of significance - LS)

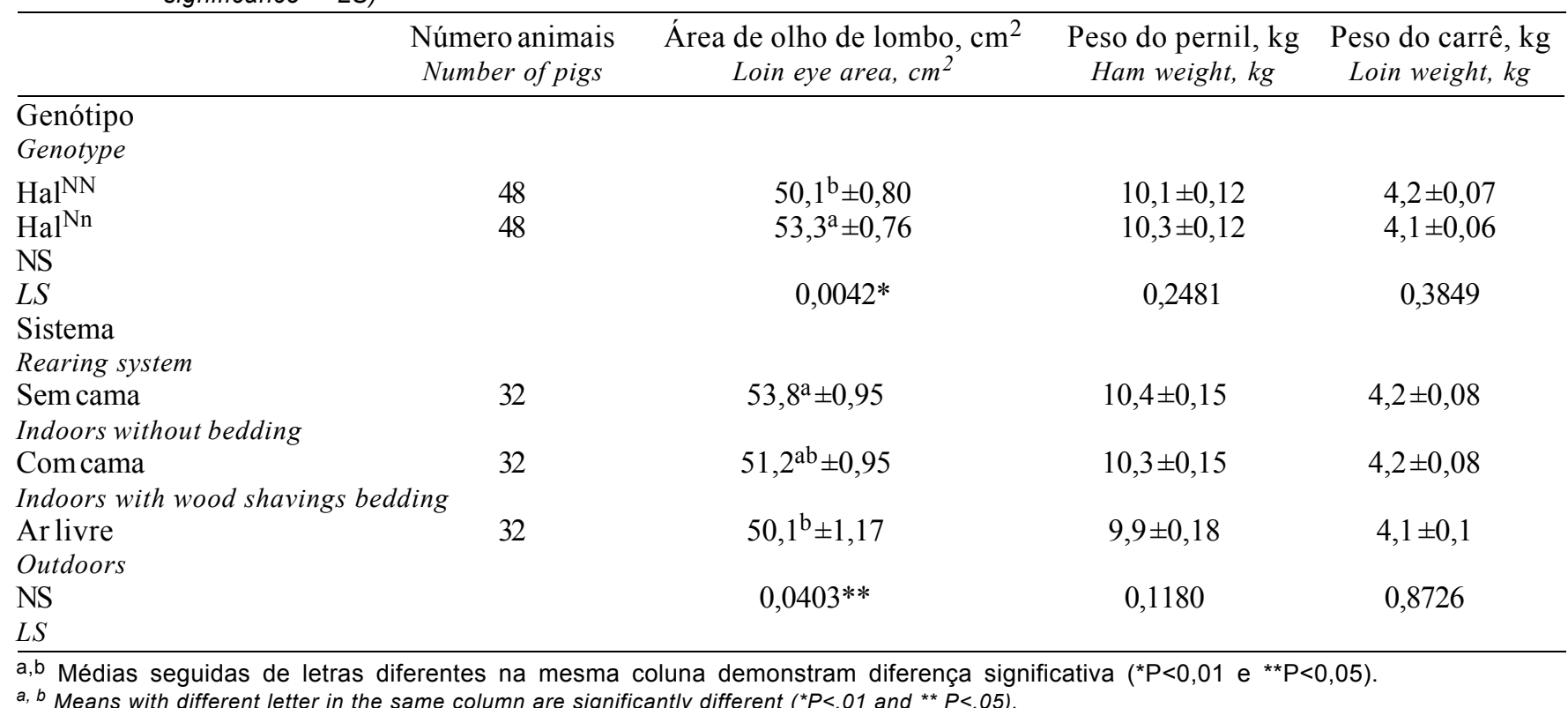

a, $b$ Means with different letter in the same column are significantly different $\left({ }^{*} P<.01\right.$ and $\left.{ }^{* *} P<.05\right)$. 
heterozigotos apresentaram menor peso de lombo e maior peso de pernil do que os suínos homozigotos dominantes. Os autores constataram que carcaças de suínos $\mathrm{Hal}^{\mathrm{Nn}}$ apresentaram maior rendimento em cortes, principalmente de pernil e paleta.

Segundo Antunes (1997), a expressão do gene halotano, ou dos genes a ele ligados, é diferente ao longo da carcaça, sendo maior no pernil e na paleta, seguido do costado posterior.

Os sistemas de criação provocaram diferenças estatísticas entre as médias de área de olho de lombo. Suínos criados em confinamento sobre piso de cimento produziram lombo com maior área do que os criados ao ar livre. Os suínos criados em confinamento sobre cama de maravalha apresentaram médias de área de olho de lombo semelhantes aos suínos criados nos demais sistemas analisados. Enfält et al. (1997) e Bridi et al. (1998) não encontraram diferença na área de olho de lombo de suínos criados confinados sobre piso de cimento e ao ar livre. Os valores médios de peso do pernil e do carrê não foram influenciados pelo sistema de criação adotado durante as fases de crescimento e terminação dos suínos. No entanto, Sather et al. (1997) verificaram que os suínos criados ao ar livre produziram lombo e pernil mais pesados que os criados em confinamento sobre maravalha, sendo essas diferenças mais pronunciadas no verão do que no inverno.

Não houve efeito estatisticamente significativo da interação entre genótipos halotano e sistemas de criação sobre a área de olho de lombo e nos pesos do pernil e do carrê de suínos.

\section{Conclusões}

Suínos criados em sistema intensivo ao ar livre durante as fases de crescimento e terminação apresentaram pior desempenho para as características ganho de peso e conversão alimentar.

O sistema intensivo de criação confinado sobre cama de maravalha provocou diminuição na quantidade de carne magra e aumento na quantidade de gordura na carcaça dos suínos.

A presença do alelo recessivo halotano não afetou o desempenho dos suínos porém aumentou a porcentagem de carne magra e diminuiu a quantidade de gordura na carcaça.

Não houve interação significativa entre os genótipos halotano e os sistemas de criação para as características de desempenho produtivo, rendimento e qualidade da carcaça suína.

\section{Literatura Citada}

ANTUNES, R.C. O efeito do genótipo hal sobre o rendimento de carne em partes da carcaça de suínos cruzados. Uberlândia: Universidade Federal de Uberlândia, 1997. 64p. Dissertação (Mestrado em Genética e Bioquímica) - Universidade Federal de Uberlândia, 1997.

BRIDI, A.M.; MÜLLER, L.; RIBEIRO, J.A.R. Indoor vs. outdoor-rearing of pigs, performance, carcass and meat quality. In: INTERNATIONAL CONGRESS OF MEAT SCIENCE AND TECHNOLOGY PROCCEDINGS, 44., 1998, Barcelona. Proceedings... Barcelona, 1998. p.114-117.

CHANNON, H.A.; PAYNE, A.M.; WARNER, R.D. Halothane genotype, pre-slaughter handling and stunning method all influence pork quality. Meat Science, v.56, p.291-299, 2000.

CHEAH, K.S.; CHEAH, A.M; KRAUSGRILL, D.I. Variations in meat quality in live halothane heterozygotes identified by biopsy samples of $\mathrm{m}$. Longissimus dorsi. Meat Science, v.39, p.293-300, 1995.

CHRISTIAN, L.L. Effect of the stress gene on quality. In: Quality sunmit. Des moines, Iowa, 1997. p.35-47.

CORRÊA, E.K. Avaliação de diferentes tipos de camas na criação de suínos em crescimento e terminação. Pelotas: Universidade Federal de Pelotas, 1998. 91p. Dissertação (Mestrado em Zootecnia) - Universidade Federal de Pelotas, 1998.

CULAU, P.O.V. A contribuição do gene halotano sobre as características de qualidade da carne suína. Porto Alegre: Universidade Federal do Rio Grande do Sul, 1999. 77p. Tese (Doutorado em Zootecnia) - Universidade Federal do Rio Grande do Sul, 1999.

ELLIS, M. Genetic and nutricional influence on pork quality. In: SIMPÓSIO SOBRE RENDIMENTO E QUALIDADE DA CARNE SUÍNA, 1., 1998, Concórdia. Anais... Concórdia: EMBRAPA, 1998a. p.25-54.

ELLIS, M. Swine breeding, sex, feeding regime, and slaughter weight and their effects on carcass lean yield. In: SIMPÓSIO SOBRE RENDIMENTO E QUALIDADE DA CARNE SUÍnA, 1., 1998, Concórdia. Anais... Concórdia: EMBRAPA, 1998b. p.55-82.

ENFÄLT, A.; LUNDSTRÖM. K.; HANSSON, I. et al. Effects of outdoor rearing and sire breed (Duroc or Yorkshire) on carcass composition and sensory and technological meat quality. Meat Science, v.45, n.1, p.1-15, 1997.

FISHER, P.; MELLETT, F. D.; HOFFMAN, L. C. Halothane genotype and pork quality. 1. Carcass and meat quality characteristics of three halothane genotypes. Meat Science, v.54, p. 97-105, 2000.

FUJII, J.; OTSU, K.; ZORZATO, F. et al. Identification of a mutation in porcine ryanodine receptor associated with malignant hyperthermia. Science, v.253, n.2, p.448-451, 1991.

GISPERT, M.; OLIVER, M.A.; TIBAU, J. et al. Prediction of carcass lean percentage from fat and muscle measurements in different breeds, halothane sensitivities and conformation classes. In: INTERNATIONAL CONGRESS OF MEAT SCIENCE AND TECHNOLOGY, 36, 1990, Havana-Cuba. Proceedings... Havana, Cuba. 1990. p.40-43.

GISPERT, M.; FAUCITANO, L.; OLIVER, M.A. et al. A survey of pre-slaughter conditions, halothane gene frequency, and carcass and meat quality in five Spanish pig commercial abattoirs. Meat Science, v.55, p.97-106, 2000.

HAMILTON, D. N.; ELLIS, M.; MILLER, K. D. et al. The effect of the halothane and rendement napole genes on carcass and meat quality characteristics of pigs. Journal of Animal 
Science, v.78, p.2862-2867, 2000.

IRGANG, R.; SOUZA, J.M.; CARDOSO, S. et al. Desempenho de suínos mestiços criados em confinamento e a campo. Revista da Sociedade Brasileira de Zootecnia, v.21, n.4, p.718-729, 1992.

JONES, S. D. M.; SCHAEFER. A. L.; DYCK, R. et al. The effects of fattening pigs in indoor pens on live performance, carcass composition and meat quality. In: INTERNACIONAL CONGRESS OF MEAT SCIENCE AND TECHNOLOGY, 39., 1993, Canadá, Proceedings... Canadá: 1993.

LEACH, L.M.; ELLIS, M.; SUTTON, D.S. et al. The growth performance, carcass characteristics, and meat quality of halothane carrier and negative pigs. Journal of Animal Science, v.74, p.934-943, 1996.

MILLER, S.A.; DYKES, D.D.; POLESKY, H.F. A simple salting out procedure for extracting DNA from human necleated cells. Nucleic Acids Research, v.16, n.4, p.1215, 1988.

MORGAN, C.A.; DEANS, L. A.; LAWRENCE, A.B. et al. The effects of straw bedding on the feeding and social behaviour of growing pigs fed by means of single-space feeders. Applied Animal Behavior Science, v.58, p.23-33, 1998.

OLIVER, M.A.; GISPERT, M.; DIESTRE, A. The effects of breed and halothane sensitivy on pigs meat quality. Meat Science, v.35, p.105-118, 1993.

OLIVEIRA, P.A.V. Produção de suínos em sistemas deep bedding: experiência brasileira. In: SEMINÁRIO INTERNACIONAL DE SUINOCUltURA, 5., 2000, São Paulo. Anais... São Paulo, 2000. p.89-100.

PERDOMO, C.C.; OLIVEIRA, P.A.V.; CASTILHO, A.B. et al. Efeito do tipo de cama sobre o desempenho de suínos em crescimento e terminação. In: CONGRESSO BRASILEIRO DE VETERINÁRIOS ESPECIALISTAS EM SUÍNOS, 8., 1997, Foz do Iguaçu. Anais... Foz do Iguaçu, 1997. p.421-422.
SAMBROOK, J.; FRITSCH, E.F.; MANIATIS, T. Molecular cloning: a laboratory manual. 2.ed. New York: Cold Spring Harbor Laboratory, 1989. v.3.

SATHER, A.P.; MURRAY, A.C; ZAWADSKI, S.M. et al. The effect of the halothane genotype on pork production and meat quality of pigs reared under commercial conditions. Canadian Journal of Animal Science, v.71, p.959-967, 1991.

SATHER, A.P.; JONES, S.D.M.; SCHAEFER, A.L. et al. Feedlot performance, carcass composition and meat quality of freerange reared pigs. Canadian Journal of Animal Science, v.77, p.225-232, 1997.

SOUZA, J.M.; SEVERO, J.L.P.; IRGANG, R. et al. Desempenho e qualidade de carcaça de suínos criados com acesso à pastagem nas fases de crescimento e terminação. Revista da Sociedade Brasileira de Zootecnia, v.21, n.4, p.718-729, 1992.

Van der WAL, P.G.; MATEMAN G.; VRIES, A.W. et al. 'Scharrel' (free range) pigs: carcass composition, meat quality and taste-panel studies. Meat Science, v. 34, p. 27-37, 1993.

WARRIS, S.C.K.; KESTIN, S.C.; ROBINSON, J.M. A note on the influence of rearing environment on meat quality in pigs. Meat Science, v.9, p.271-279, 1983.

Recebido em: 06/05/02

Aceito em: 06/01/03 